\title{
Comparison of Chinese and Westerners' Communication Pattern
}

\author{
Lijun Yang \\ School of Business and Trade \\ Huanghe Science and Technology College \\ Zhengzhou, China \\ e-mail: 379630960@qq.com
}

\begin{abstract}
As a result of Chinese and Western culture's difference Chinese and Westerners' communication has easily formed into the awkward and even embarrassed conditions. Along with the quick change of the whole world's process of integration, the breadth and the depth of Chinese and Westerners' communication are developing and deepening unceasingly, therefore it is necessary for us to carry on the contrastive analysis of Chinese and Westerners' communication patterns in order to promote smoothly the Chinese and Westerners' communication. This article has made the contrastive analysis of series of quite remarkable differences of Chinese and Westerners' communication process, which involve the main communicating modes: language; the different meaning expressed by expression and posture; regarding acceptance of praises, thanks, expression of separation; dines, sending gift and so on. Through these analyses, this article promulgates the importance of culture in the communication, believes we should understand different cultures of different countries and then the bilateral communication will be more relaxing and happy. In the Chinese and Westerners' communication, it is necessary to know the difference and learn to adapt the difference gradually. Under the present situation, it is Chinese and Westerners' communication law of development from the conflict to the fusion.
\end{abstract}

Keywords-Chinese and Westerners; communication patterns; culture

\section{INTRODUCTION}

A beyond doubt the truth is that Chinese and westerners' communication is a Trans-Cultural communication; but in the final analysis, different cultures decide different communication patterns. The culture is a system shared by belief, value and behavior, it is the activity used by the members of different social classes to deal with surrounding of the world and respective relations. It is handed down from generation to generation through the study in daily life. Its definition concludes such following aspects: the behavioral patterns, the thought patterns (a social member can be influenced by the common natural phenomena and intelligent phenomena), the artificial products (tools, earthenware, machines, and arts), the technology and the method used to make these artificial products. (Daniel and Freg 78)The anthropologist William ever suggested: "people will make use of the culture to deal with each kind of related issue." It means that the culture should meet the primary need, including the communication need without doubt. The communication is inevitable in the human society, the human is impossible to be isolated from other people completely in the world; therefore the suitable communication patterns facilitate all things to be simply. The communication may be easier when the both parties understand the background and culture of opposite party well. This kind of communication being familiar with bilateral cultures will make the life become very easy and happy, and thus cause the entire world to become no longer mystical and strange. Especially at present the communication between different countries is frequent day by day. Therefore, it is more and more important for us to understand the communication patterns under the background of Chinese and Western culture.

\section{COMPARISON OF ChINESE AND Westerners' GreEtings}

The greetings are the beginning of communication, the good greetings may make a good impression effectively on the opposite party, and it is conducive to the later activity of communication. The author will make an analysis of greetings with spoken language, body language, and facial expression, expression in one's eyes and other postures to study Chinese and Westerners' communication patterns.

\section{A. Spoken Language}

As a result of cultural and customary difference, Chinese and westerners will use the different spoken language when extending cordial greetings. If the Chinese does not understand the Western custom and utilize the familiar custom of their own to greet the westerners, then usually the westerners may feel muddled or very awkward, vice versa. When the westerners meet each other, familiar and unfamiliar person greet each other with different patterns. If they run into an unfamiliar friend, they will only say "Hi!", "Good morning (afternoon)" or "Hello!" and so on. If it is their first meeting, they will say "How do you do?", but not the "How are you?". If they meet with a quite familiar friend, they will discuss frequently some topics such as the related weather, the transportation and the test and so on. But, with reference to Chinese, if they run into an old friend, they will say frequently "hello, my old friend, these days you have become fat." Or in a very friendly way, "you are thin; you should pay attention to your body." Hearing these words, the people will not be angry. 
But when the westerners hear these words, although possibly they are very familiar, they will be very awkward; they do not know how to reply them, because these questions are not very polite for them. When the Chinese meet with each other, the first few words usually are "have you taken a meal?", if the westerners hear these words, they will think that you want to invite them to a dinner. Even if you see him eating a meal, you should not say "You are having a breakfast?" They will regard this phrase as useless words in the West. If a Chinese runs into a westerner who is repairing a vehicle, you would rather say "Hi!" or "hello!" than "You are repairing your car?". If you speak the latter, the westerner will stare at you and be full of puzzle, he will possibly reply "Yes!", but in fact he is thinking at heart "do you have any problem? Even if you have seen what I am doing, why you ask so yet." If the Chinese people is going to enhance his spoken language, he may say that "you are really a good mechanic" or "can I help you?" or "Do you have a rest?" at the same time it is wise of him not to be too talkative so as not to disturb others too much.

\section{B. Body Language}

When you communicate with a person who has the different cultural context, it is essential for you to understand another language. Two persons can not communicate well, without proper understanding. A person under one cultural condition maybe expresses his sentiment less openly than a person under another cultural context, but it does not mean that the former does not own the sentiment. Accurately speaking, the non-language's performance has the limit of culture.(Mitchell 36) If we make an adjustment of the person who uses different body languages to express sentiment according to our own cultural criterion, we will make a mistake. When meet with each other, Chinese may shook hands warmly, a Westerner may warmly embrace, but the later often happen between two lovers, two relatives, or two familiar friends in China. In China or many other countries, a nod can express an agreement and shaking the head is able to express the opposition, but in Sri Lanka, Nepal, Bulgaria, Algeria and Greece and so on, the situation is just the opposite. Indian shakes the head and turns around his head to one side express the agreement or the approval. When calling somebody to come, there is also the cultural difference. A Chinese outstretches one of his hands and wields the finger, the palm faces down. But in Britain and the US, this kind of posture is used to call the beasts. In China and many other countries, the people express "good" or "ok" with the thumb, but in Australia, this is actually an uncouthly behavior. In China, people less kiss each other with exception the lovers, if one kisses the unfamiliar people, he may be regarded as a peculiar and mad person; but in the West a kiss may be considered as a politeness, not only the lovers may do it, but also the friends, the family, even the unfamiliar people.

\section{Facial Expression}

The facial expression expresses the importance which is decided by the scene and the relations also. For example, in the America, the smile is the typical symbol of happy. However it has other functions similarly. The smile may express the affection, the politeness, or the concealed real sentiment. It is also one of the confusing aspects in the Trans-Cultural human relations. For example in China, many people think that it is unusual to smile on the stranger in the public area, even it is a doubtable behavior. However many Americans smile on the strangers comfortably in the public area. Some Chinese think that the American's smile at the mistake place, but the Americans maybe think that the Chinese smile insufficiently. Moreover in some places in China, the smile even may be used to express the pains or awkward.

\section{Expression in one's Eyes}

The pattern of expression in one's eyes has different meanings in each culture, in Western culture it is not polite to gaze into the people's face, particularly the strangers'. Usually some westerners regard Arabic or Indian communication pattern with reference to staring at someone as uncomfortable communication. To them, this kind of expression in one's eyes is full of anxious. However insufficient expression in one's eyes is considered similarly as a bad deed, without the expression in one's eyes, usually without deficient interest, attention or even distrust. The relations between insufficient expression in one's eyes and distrust usually may be expressed by the following words, "You should not believe the one does not dare to look at you". On the contrary, in other places of the world, such as in China one should stare fixedly at the leader and lower one's head when the leader talks to him, otherwise the leader will consider he do not respect him.

\section{COMPARISON OF CHINESE AND WESTERNERS' RECEIVING PRAISES, THANKS AND LEAVING}

If people can make proper expressions of receiving praises, thanks and leaving, the communication will be improved efficaciously. This article will make the comparison of Chinese and Westerners' communication patterns through comparing with Chinese and Westerners' expression of receiving praises, thanks and leaving in this chapter.

\section{A. Receiving Praises}

According to the different cultural backgrounds, the people usually have the different response to their praises received. In the Western country, it is very polite to commend a young lady's semblance and intelligence. For example, a Westerner usually says "You are so pretty today!", "You have a beautiful smile." and "You look wonderful this evening." and so on. But in China, the meaning is far from it. If a man in the public area commends a young lady's semblance, others will think this person maybe have evil intentions or be not polite. Therefore regarding the response to praises correspondingly is different too. The westerners will reply "Oh, I'm very glad you like it.", "Thank you very much!", "I' m glad to hear that." and so on. But the Chinese will reply frequently "Oh, no" or "I am not beautiful at all." These two kinds of replies originate from their different traditional cultures. Just "modest" is Chinese nation's moral excellence, but in Western culture too much modest is useless, they advocate the "victory" and the "hero" all the while. 


\section{B. Expressing Thanks}

In China when the people go shopping, go to the restaurant, hotel or utilizing transportation vehicle, they frequently say thanks to the shop employee, the service person or the driver in order to express their sense of gratitude to the service. But in the Western country, the shop employee, the service person and the driver will say "thanks" to the customer in order to welcome their presence. Sometimes words of thanks lead to unhappiness on the contrary. For example, an American teacher has spent many time on reading your paper, you might say "Thank you very much. I really appreciate your help." It is ok enough. But if you utilize China's grateful pattern and add one again "I'm sorry to have wasted so much of your time." These words will make this teacher feel very awkward. He possibly believes that his help is useless and only wastes the time in your opinion. As a result he will not be happy and is not willing to help you again.

\section{Leaving}

Chinese and Westerners may separately use the different language to express the leaving. In Western country, if a person wishes to leave, he may politely say: "Well, I' m afraid I must be going now." even if he knows the master is really very tired, as a result he hopes that he may have a earlier rest, then the visitor should not say: "I had better be going now, you must be very tired." such words only may be said when the master fall ill truly. In China, when the master hopes his visitor again stays a while, but the visitor insists on leaving, the visitor will say: "I have already wasted your so much time." Or "I am sorry; I have taken you so much time." On the contrary, under this condition the westerners will say: "Thank you for a lovely afternoon." or "It's good to see you again." After others have spent much time on helping you to do some thing, you are able to say: "I' $m$ sorry to have taken up so much of your time." As is well known that there is a kind of custom in China, when the visitor wants to leave, almost all members of the family will see the guest to the door, to the road or to the station, then say again and again good-bye. Finally, the master may also say: "please walk slowly", "welcome to come next time" or "watch your steps" and so on. In the West, the master sees a visitor to the entrance merely, at the same time it is not necessary to say such words as "please do not bother you and come here any further.", "please do not bother to see me off" and so on. They will not always see you to the downstairs or the station, only if you request them to do such things. It is not because the westerners are not warmhearted, but only the cultural difference.

\section{COMPARISON OF CHINESE AND WESTERNERS' MAKING FRIENDS}

The westerners and Chinese may become the friends in the good process of communication, after being the friends, their communication need be continued, at this time because of the cultural difference, the pattern which the Westerners and Chinese make friends still need our further study.

\section{A. Making Dinner}

At present more and more Westerners go to China to work, travel or live, at the same time the opportunity of leaving one's native land has increased for Chinese people. Therefore, there is too much chance for Chinese and the Westerners to become food friends. For this reason, Chinese should study some hobby and custom of the Westerners.

1) The Wsterners should understand that some words are not the invitation truly.

For example: "Please stop at any time, we can have a talk.", "We can have a dinner sometime, I will call you." or "Let us get together sometimes." and so on in China, such these words only indicate that they want to finish the talk and you had better leave as soon as possible.

2) The Chinese and the westerners have different fondness offood and drink.

There is an axiom in the West: eat to live, but do not live to eat. Possibly as a result of this, the westerners pay attention to the nutrition of food and drink. They eat well, but not complexly. Under normal conditions, they only have 2 or 3 courses; it is just the opposite of the Chinese. Usually the westerners invite their friends to have a meal only in order to talk. They have prepared many foods beforehand, for example some sweets and salad. Therefore when the visitors arrive at the appointed time, they may begin to talk mutually. The westerners do not mind which position they should sit at. You can sit at anywhere that the master arranges you to sit. After the food, the master usually gives you a coffee. But in China, the master will leave a so called important position for one owning the highest status; usually it is opposite to the door. In Western culture, if a ready-to-cook dish places in front of you, although you possibly do not like it, you had better taste one.

3) Inviting the visitors to have a meal also has another very big difference.

Ggenerally speaking the Chinese is very hospitable and clamps the vegetable with theirs chopsticks to the visitor. Looking from the westerner's angle, we can find this is not very polite and unsanitary. They usually say: "Help yourself please." When dines, it doesn't matter to them whether you smoke or not in China, but in the West, if you want to smoke, you had better ask: "Would you mind if I smoke?" If others do not mind, you may have a smoke; otherwise it is not polite, particularly in front of the young ladies. In addition, a big difference of making dinner is drinking, Chinese often urge the visitors to drink, and more liquor of the visitors drink can express more enthusiasm of the masters; the volume of drinking on behalf of the degree of sentiment. But in the West, they will not drink too much, except the visitor himself want to drink.

\section{B. Giving the Gift}

When a Chinese people have become friends with a westerner, he possibly makes a present mutually, but if he does not understand the difference of Chinese and Westerners, the good wish instead will work just the opposite. Do not think what you like others will like similarly too. For example, in China we have the tradition of respecting old person. Because we think that the old person has more wisdom and owns very high status thus, therefore we wish the old person to have 
"happy and great good fortune" always. The longevity has become a very good wish. But in the West, there are very few people willing to be called "old person". When they are old, they live alone in order to be independent in the West. They hate others to call them "old person". They have such faith: it is good to own knowledge and experience, but it is better to own the youth and vigor! Here is an example: in America a Chinese student sent an "old longevity god" to his teacher when the birthday of his teacher comes. But when his teacher received the gift, he said seriously: "do you hope that I am equally old with that person? I am willing to be forever young."(Larrry 132) The westerners think it is polite to open a present in front of the human. So when you receive the Western friends' gifts, you should immediately open it in order to indicate that you are interested very much in this gift, and you may express thanks immediately, you may say: "Thank you very much. I really like it very much." But in China, people will always open the gift after his friends have left. Seeing above examples, we may find such difference is very great.

\section{CONCLUSION}

From the above analysis, we can understand the culture is very important, especially during the communication. If you understand different culture of different countries, it will become easy for you to communicate with others. If you do not understand them, it will be annoyed trouble. Understanding different cultures and more knowledge will help you to do well in many domains, it will be quite important for you to obtain success. Therefore in essence Chinese and Westerners' communication is the communication of Chinese and Westerners' two kinds of cultures. Cultural communication of Chinese and Westerners is the contact, the dissemination and the interaction will happen between the Chinese mainstream culture and the Western mainstream culture. The cultural communication and fusion are the prime motive force of cultural development; For Chinese and other nation, nationality's cultural communication is one of important driving force of these countries' cultural development. Under the globalizing background, the distance to the world is more and more close at present, the "global village" has been formed. Any country wish to support oneself in the forest of the world and the nationality, the cultural communication is the unavoidable fact. The globalization provides the delicious opportunity of the cultural communication and the strength of pushing to the contemporary China and the West; certainly there are both hope and difficulty. It will never stop the step of one kind of culture to close its doors to the rest of the world, changes come under attack of different cultures inevitably; the initiative of cultural communication will be stronger, the culture will revive more possibility. In fact if we do not carry on the cultural communication on our own initiative, then our culture will tend to be marginalizing or withering away; the communication patterns change from the conflict to the fusion is the law of development of Chinese and Westerners' cultural communication.

\section{ACKNOWLEDGMENT}

I would like to give my heartfelt thanks to many people for their help in my academic studies over the past years.

My deepest gratitude to my family, thanks for their kindness, patience, encouragement. Thanks to my school that has give me this delicious opportunity. And thanks to my dear friends who have given their great help to me in my research.

\section{REFERENCES}

[1] Ali A. Mazrui. Cultural Force in World Politics, New Hampshire: Heinemann Educational Books Inc., 1990.

[2] Daniel. G. Bates and Freg Plog. Cultural Anthropology, New York: Mc Grawltill, 1990

[3] Frank A. Ninkovich. The Diplomacy of Ideas: U.S. Foreign Policy and Cultural Relations, Cambridge: Cambridge University Press, 2001.

[4] Frederick Charles Barghoorn. The Soviet Cultural Offensive: The Role of Cultural Diplomacy, Washington: Westport Greenwood Press, 1996.

[5] George Sarton. Introduction to the History of Science, London: Wadsworth Publishing Company, 2000.

[6] Herbert Passim. China's Culture Diplomacy New York: Frederick A. Praeger Publishers, 1990.

[7] J.M .Mitchell. International Cultural Relations, London: Allen\&Unwin Ltd, 1986.

[8] Larrry A.Samovar. Communication Between Cultures, London: Wadsworth Publishing Company, 2006.

[9] P .McMichael. Development and Social Change, New York: Pine Forge Press, 2000.

[10] T.L. Friedman. The Lexs and the Olive Tree, New York: Farrar, Straus and Giroux, 1999. 